\title{
Changes in Microfungal Community in Cherrapunji - The Wettest Patch on Earth as Influenced by Heavy Rain and Soil Degradation
}

\author{
Purabi Saikia, Santa Ram Joshi* \\ Microbiology Laboratory, Department of Biotechnology and Bioinformatics, North-Eastern Hill University, Shillong, India \\ Email: "srjoshi2006@yahoo.co.in
}

Received August 7, 2012; revised September 17, 2012; accepted September 30, 2012

\begin{abstract}
As part of a long time analysis to examine the ecological impacts of heavy rain coupled to soil degradation, soil fungal communities from two closely spaced sites bearing distinct ecology—one receiving heaviest rainfall but degraded patch on earth and the other pristine sacred grove forest were investigated over a period of three years. Cherrapunji besides being highest rainfall receiving area, is characterized by complete deforestation and soil erosion with sparse grasses forming the surface growth, whereas the sacred forests are conserved in their pristine nature due to religious beliefs of the indigenous tribes. The effect of deforestation and land degradation on soil microbes, soil organic carbon, soil nitrate nitrogen, soil $\mathrm{pH}$, soil temperature, and fungal $\mathrm{CFU} / \mathrm{g}$ were investigated from the two contrasting sites. The sites showed great variability in physical and chemical parameters including soil composition, temperature, $\mathrm{pH}$, soil carbon, nitrogen content, water availability and enzyme activities. The population count of fungi was higher in sacred forest soil than degraded land of Cherrapunji. In both soil types, Penicillium perpurogenum markedly dominated and the co-dominant species (Aspergillus sp., Fusarium sp. and Trichoderma sp.) were common in both virgin and degraded soils. A total of 63 species were identified during the study period. The species composition between the two sites showed some variation as Syncephalastrum sp., S. chartarum, Gliocladium sp., Eupenicillium osmophilum and Eurotium sp. were not present in Cherrapunji. The undisturbed sacred forest fungal communities had significantly higher Simpson, Shannon and evenness indices than that of degraded soil of Cherrapunji. The prolonged anthropogenic activity in the area leading to degradation coupled with heavy rainfall has decreased the diversity level of fungal communities and masked the pristine differentiating effect of soil on the fungal community.
\end{abstract}

Keywords: Microfungal Diversity; Sacred Forest; Heaviest Rainfall Area; Degraded Land; Cherrapunji

\section{Introduction}

Soils provide a complex microhabitat for harboring diverse groups of microorganisms $[1,2]$ and a number of studies point to the inherently complex compositional structure of soil microbial communities $[3,4]$. Microorganisms play an important role in nutritional chains that are an important part of the biological balance in the life in our planet and their activities are regulated by biotic and abiotic factors such as the quantity and quality of litter inputs, temperature, moisture etc. Atmospheric and climatic changes have an impact on both abiotic and biotic drivers in ecosystems and the response of ecosystems to these changes. Feedbacks from ecosystem to the atmosphere may also be regulated by soil microbial communities [5]. Fungi are important in ecosystem functions such as in organic matter decomposition processes

"Corresponding author.
[6]. In the microbial communities of soil, fungi play important roles in decomposition via soil nutrient recycling and the accumulation of soil organic matter [7]. Fungi are an important component of the soil micro-biota typically constituting more of the soil biomass than bacteria, depending on soil depth and nutrient conditions. Reports are available on the environmental and geographical influences on the structure of terrestrial and aquatic microbial communities [8]. However, literature on the relative contributions of geographical distance and environmental habitat is limited.

Disturbance is a common feature of many ecosystems, occurring at all levels of ecological organization and at numerous temporal and spatial scales [9], and may be anthropogenic or natural. Natural disturbance, from seasonal changes in rainfall and tree fall, to hurricane damage, cause population shifts and changes to communities of fungi [10].

Cherrapunji in Meghalaya, India, is the wettest place 
on earth but there is very little forest left on this vast plateau. What is left of the subtropical, broadleaved evergreen forest is mainly in the form of patches, most of which are treated as sacred groves by the ethnic communities. The patches are found on the plateau itself and on the steep slopes of gorges and cliffs. Such forests are very rich in biological diversity and harbor many endangered plant species including rare herbs and medicinal plants [11]. Much of the Cherrapunji region has been degraded through forest clearing for shifting cultivation, and many previously forested slopes are now grasslands. These grasslands are maintained under high stress conditions of thin soil cover, highly leached nutrient-deficient soils, frequent fires, and low soil moisture retention in spite of a high average annual rainfall of $11,000 \mathrm{~mm}$. The cultivation practices, overgrazing, and high rates of sheet flow, produced by heavy rain falls accelerate soil erosion, which has caused a substantial degradation of the upper soil profile. We assume that prolonged anthropogenic activity in the area might decrease the diversity level of microbial communities and mask the pristine differentiating effect of soil on microbial community.

Although much is known about the arid fugal diversity, few researches have directly compared the fungal communities of arid soils with undisturbed protected soils like the sacred forest soil and this is the first report on comparative microfungal study in this part of the world. The objective of this study was to explore the composition of fungal communities in representative soil samples collected from disturbed and undisturbed soil from Cherrapunji, the highest rainfall receiving patch on planet earth and assess if there is a community shift induced by rainfall, erosion and soil degradation.

\section{Materials and Methods}

\subsection{Site Description}

The study area, Cherrapunji is located in the NorthEastern part of India. It has an average elevation of 1484 metres $(4869 \mathrm{ft})$. The cliffs of Cherrapunji receive heavy rainfall due to monsoon winds blowing from the Bay of Bengal. The climate in the region is moderate because of higher elevation. Cherrapunji's yearly rainfall average stands at $11,070 \mathrm{~mm} /$ year. Degraded rocky landscape of Cherrapunji is covered by sparse grasses while the sacred grove is covered by different herbs, shrubs and trees (mixed vegetation). The soil profile of degraded land is reddish, dry and rock sandy while the sacred groves have brown to black, clay and loam in texture.

\subsection{Sampling}

The soil samples were collected from degraded areas of Cherrapunji and adjacent sacred groves in four different seasons from 2008-2011 during the study: Mar-May, Jun-Aug, Sep-Nov. and Dec-Feb. The sampling at both the sites was done on bimonthly basis and the data presented as average of all the observations. Different physical parameters of the sampling site were recorded. The ambient temperature and humidity was recorded using a Hygrometer. The altitudes of the sampling sites were determined by using GPS (Garmin 76 CSX). The microbial community represents the total isolates characterized during each sampling period. Top soil $(5 \mathrm{~cm})$ was scrapped off and about $200 \mathrm{~g}$ soil samples were collected from three locations of each site, mixed thoroughly, put in sterile polythene bags and the samples were analyzed in the laboratory. Appropriate sterile materials were used and sterile conditions were maintained during the study.

\subsection{Isolation and Identification of Fungi}

The colony forming units of the fungi were determined by serial dilution method. $10 \mathrm{~g}$ of the soil sample was suspended in $90 \mathrm{~mL}$ of sterile $0.9 \% \mathrm{NaCl}$ solution and shaken vigorously on a magnetic stirrer for 30 minutes to obtain uniform suspension. A serial dilution upto $10^{-5}$ was made and $0.1 \mathrm{~mL}$ aliquot from each dilution was inoculated on Potato Dextrose agar (PDA, HiMedia, India) plates and incubated at $25^{\circ} \mathrm{C}$ for $48-72 \mathrm{~h}$. All fungal colonies which appeared on plates were counted. Morphologically different strains were isolated and purified, maintained on PDA slant and stored at $4^{\circ} \mathrm{C}$ until further use. Identification of the fungal isolates was carried out on the basis of their macro- and microscopic characters using standard manuals [12-14].

\subsection{Soil Physical and Chemical Analyses}

Soils samples were weighed and dried in the oven (24 hours at $105^{\circ} \mathrm{C}$ ) and the dried soils were weighed. The difference in their weight was recorded and calculated as moisture content $(\%)$. pH was measured in water paste $(1$ soil:5 water) by a digital $\mathrm{pH}$ meter. Water content and $\mathrm{pH}$ were measured in all seasons. Soil carbon and nitrate nitrogen were estimated by using the soil testing kit (Himedia, India).

Soil enzyme activity was used as an indicator of microbial activity. Acid phosphatase was determined on the fresh soil samples by the procedure of Tabatabai and Bremner [15]. 2, 3, 5 Triphenyltetrazolium chloride (TTC) reduction technique was adopted for the evaluation of dehydrogenase activity of soil [16]. McGarity and Myer's [17] method was followed to measure the urease activity in soil.

\subsection{Diversity Analysis}

The diversity of the culturable fungi was estimated using 
the Simpson's, Shannon's diversity indices and species evenness. Simpson [18] proposed the first index of diversity in ecology. The index is appropriate for sampling from finite ecological units. The Simpson index, $D$ which varies from 0 - 1 is given by:

$$
\begin{aligned}
& 1-D \\
= & 1-\sum n i(n i-1) /[N(N-1)] i \\
= & 1
\end{aligned}
$$

where $n i$ is the number of individuals in the $i^{\text {th }}$ species, $N$ the total number of isolates. The reciprocal form of Simpson's index $(1 / D)$ usually is presented, ensuring that the index increases with increasing diversity.

The Shannon Index of diversity $\left(H^{\prime}\right)$ [19] is the most popular index in community ecology and is given by:

$$
H^{\prime}=-\sum_{i=1}^{s} p i \ln p i
$$

where, $p i$ is the proportion of species $i$ in a sampling plot. Evenness, $J$ that measures the equity of the presence of each species in all the samples, is given by $J=H / H_{\max }$, where $H_{\max }$ is the maximum value of $H$ for the number, $S$, of species present; $H_{\max }=\ln S$.

Paleo-ecology statistics freeware package (PAST) [20] was used to estimate the Shannon diversity index $(H)$, Simpson's index $(D)$, and evenness $(J)$ of the two designated sites.

\subsection{Statistical Analysis}

All the tests were performed in triplicates. The results are expressed as mean $\pm \mathrm{SE}$ values and data were tested by one-way analysis of variance. Differences were considered significant at $p<0.05$. Correlations were calculated for soil $\mathrm{pH}$, moisture content, soil temperature, ambient temperature, humidity and fungal population count using Karl Pearson's coefficient.

\section{Results}

\subsection{Soil Physical and Chemical Analyses}

The physical and chemical properties of soil in sacred grove forest differed from that of degraded land of Cherrapunji. Differences in water content between the soils in the winter were low, whereas in the summer the values were more than 2-fold higher in the soil of sacred forest. Soil carbon content and nitrate nitrogen contents were high in the soil of undisturbed forest whereas it is low on degraded land. Soil temperature, as well as ambient temperature was found to be higher in degraded land than that of forest area, whereas humidity was found to be high in forest than degraded area. Although there is not much difference in $\mathrm{pH}$ values of both soil types, the $\mathrm{pH}$ of the degraded land was found to be high in comparison to forest soil (Table 1). The soil dehydrogenase, urease and acid phospahatase activities were higher in the pristine sacred forest soils than the degraded soil of Cherrapunji (Figures 1-3).

\subsection{Fungal Colony Forming Unit and Species Composition}

Fungal population count was higher in rainy season as compared to the winter. However, CFU/g dry soil was higher in sacred forest soil than degraded soil irrespective of the seasons (Figure 4). A total of 63 fungal species were isolated during the study period. The soil mycobiota of the studied area comprised of Zygomycota (7 species) and Ascomycota (56 species) (Table 2). The species belonged to 29 genera, most prominent were Penicillium (17 species), Aspergillus (7 species), Fusarium (4 species), and Trichoderma (3 species). The variation in species composition between the two sites showed some variation in that Syncephalastrum sp., S. chartarum, Gliocladium sp., Eupenicillium osmophilum and Eurotium sp. were present only in sacred forest soil

Table 1. Physico-chemical parameters of the two different soils types.

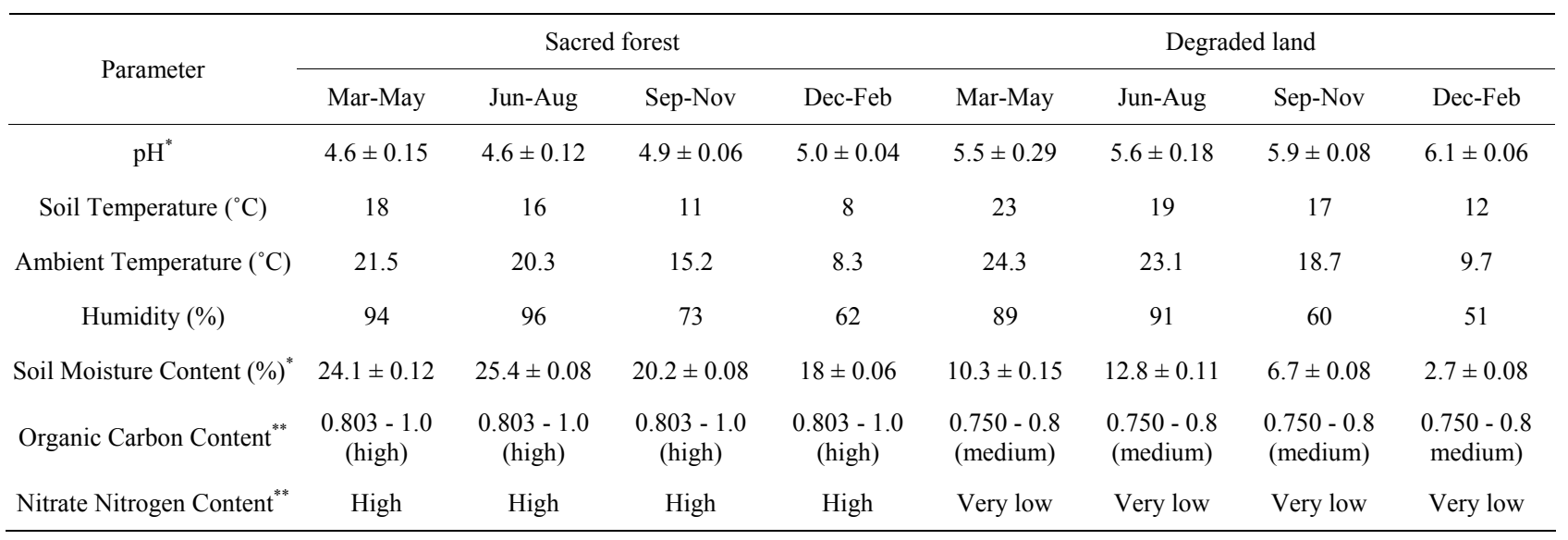

${ }^{*}$ Values are average of three replicates $\pm \mathrm{SE} .{ }^{* *}$ values interpreted based on test kit (Himedia, India). 


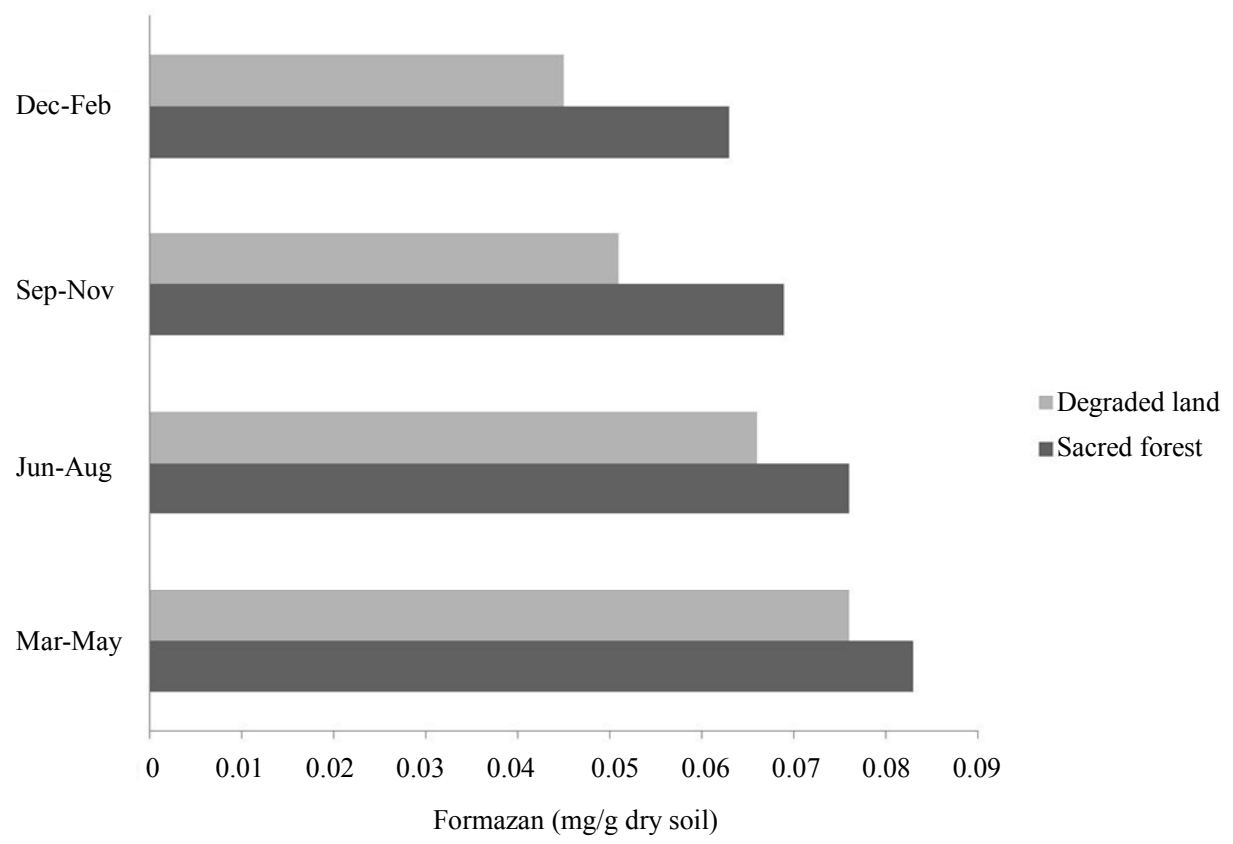

Figure 1. Soil dehydrogenase activities of sacred forest and degraded land soils.

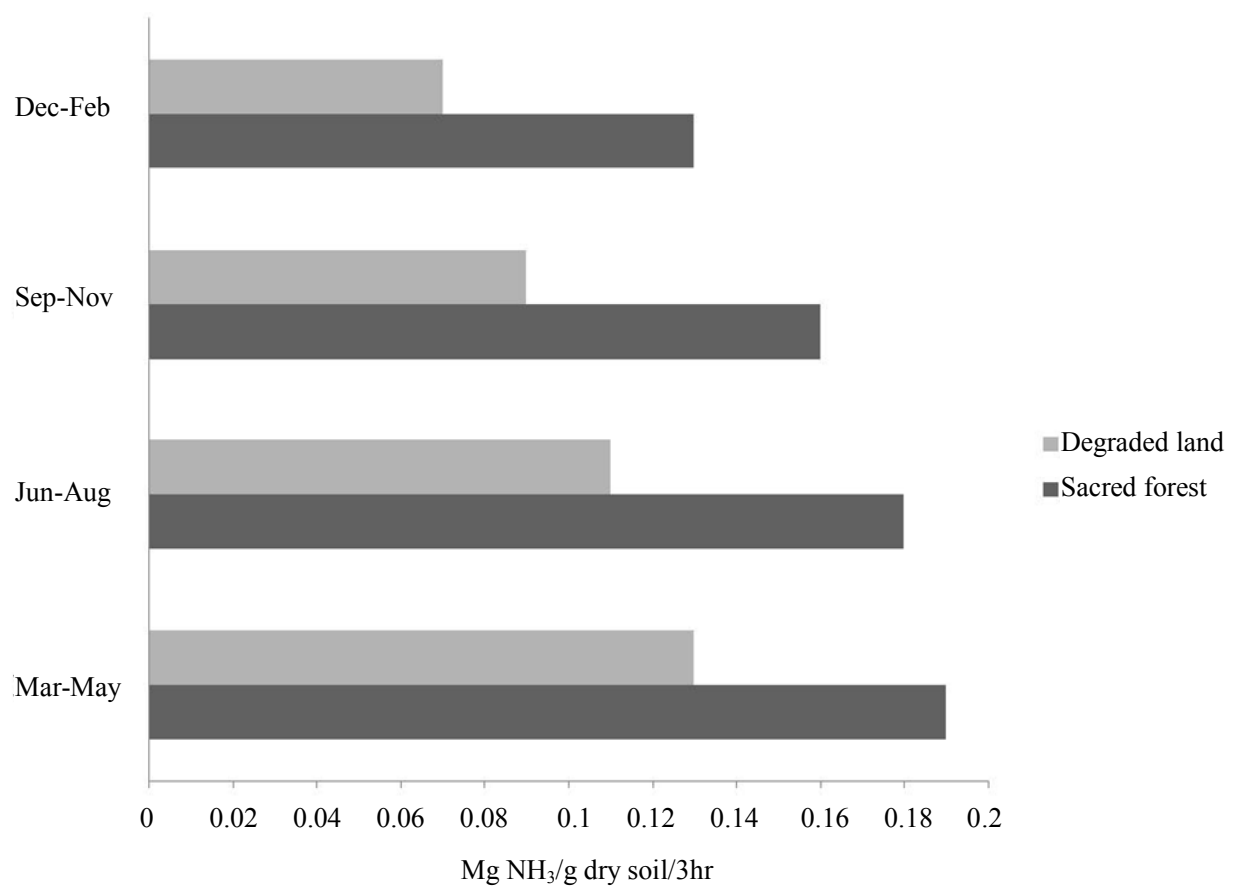

Figure 2. Soil urease activities of sacred forest and degraded land soils.

but not in degraded soils of Cherrapunji. Higher relative abundance was observed in summer months while winter had lower relative abundance in both the sites.

\subsection{Diversity Characteristics}

Significantly more fungal species (59\%) were isolated from sacred forest soil than the degraded land (41\%). Seasonal changes in species richness were inconspicuous except winter. The undisturbed forest fungal communities are characterized by significantly higher Simpson, Shannon and evenness indices than those in the soil of disturbed area (Table 3).

\section{Discussion}

The present study revealed considerable changes in the soil characteristics and differences in microbial commu- 


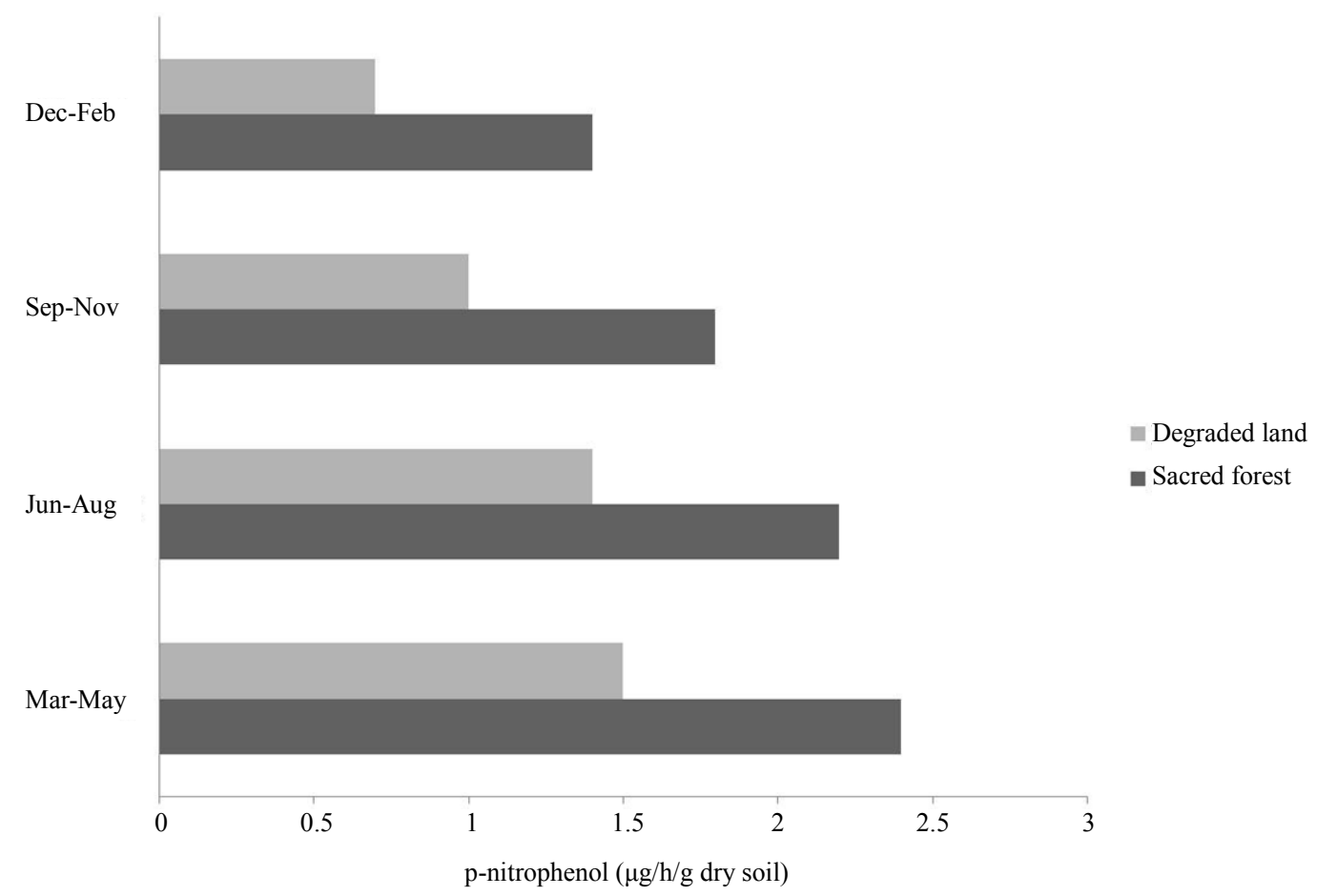

Figure 3. Soil acid phosphatase activities of sacred forest and degraded land soils.

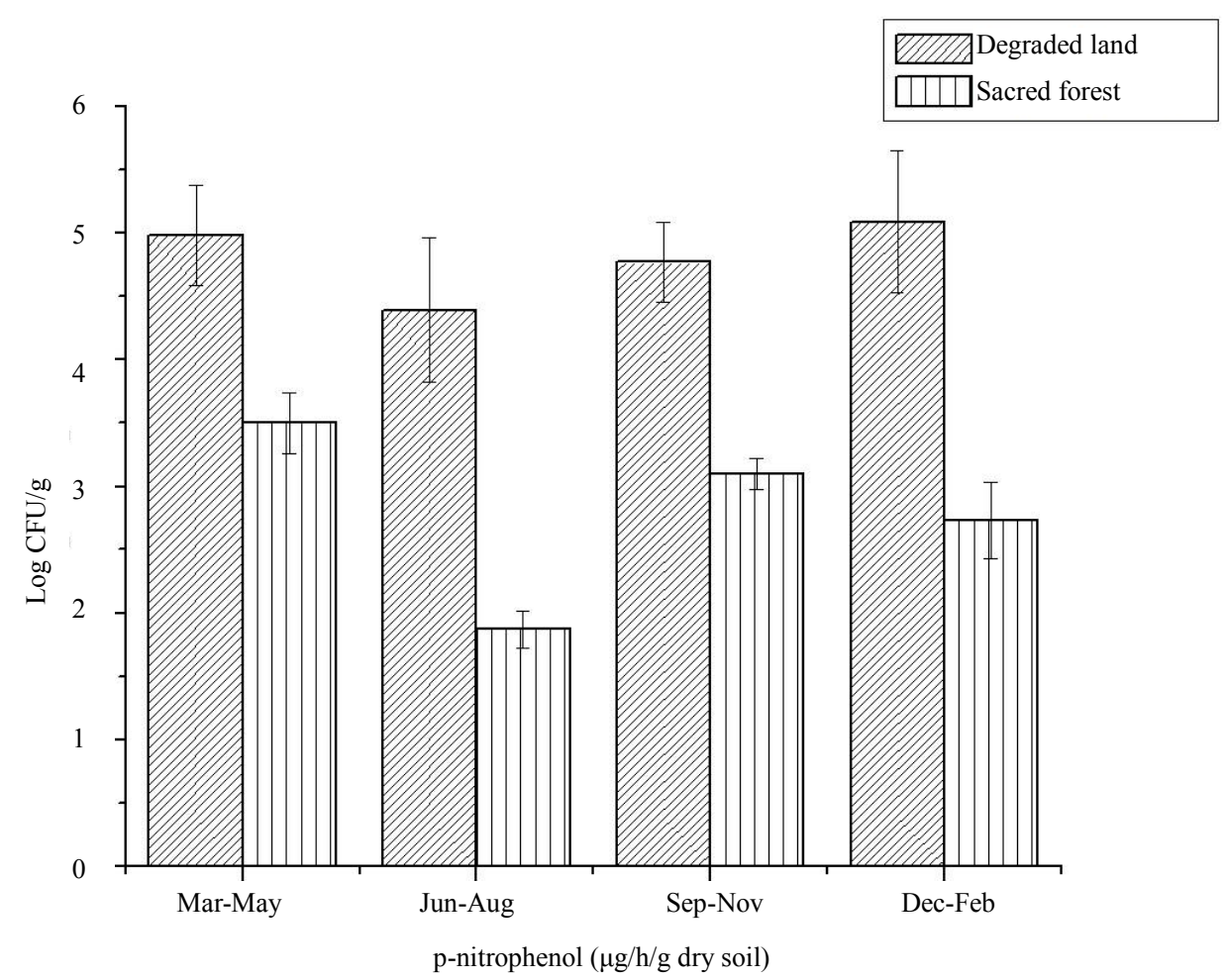

Figure 4. Colony forming unit (log/g dry soil) of sacred forest and degraded land soils.

nities between the two sites. A significantly high fungal count $(\log \mathrm{CFU} / \mathrm{g})$ was recorded in forest soil than degraded soil of Cherrapunji. Environmental stresses brought by drought could be the factor for reduction in microbial population and diversity in degraded land soils. Plant species composition is a factor influencing microbial community composition [21]. A number of studies have addressed soil microbial growth, population den- 
Table 2. Relative abundance of soil fungi from sacred forest and degraded land.

\begin{tabular}{|c|c|c|c|c|c|c|c|c|}
\hline \multirow{2}{*}{ Species } & \multicolumn{4}{|c|}{ Sacred forest } & \multicolumn{4}{|c|}{ Degraded land } \\
\hline & Mar-May & Jun-Aug & Sep-Nov & Dec-Feb & Mar-May & Jun-Aug & Sep-Nov & Dec-Feb \\
\hline \multicolumn{9}{|l|}{ Zygomycota } \\
\hline Mucor circenelloides & 0.03 & - & - & - & 0.15 & - & 0.12 & - \\
\hline M. racemosus & - & - & - & - & - & - & - & 0.04 \\
\hline Rhizomucor variabilis & - & 0.05 & - & - & 0.04 & - & - & - \\
\hline Rhizopus stolonifer & - & 0.03 & - & - & 0.03 & - & - & 0.04 \\
\hline Rhizopus sp. & - & - & - & - & 0.03 & 0.12 & - & - \\
\hline Absidia spinosa & 0.03 & - & - & - & - & 0.04 & - & 0.04 \\
\hline Syncephalastrum racemosum & - & 0.16 & - & - & - & - & - & - \\
\hline \multicolumn{9}{|l|}{ Ascomycota } \\
\hline Aspergillus niger & 0.24 & 0.27 & 0.21 & 0.05 & 0.38 & 0.35 & 0.19 & 0.04 \\
\hline A. terreus & - & - & - & - & 0.04 & - & - & - \\
\hline A. fumigates & 0.03 & - & - & - & - & 0.04 & - & - \\
\hline A. flavus & 0.03 & - & - & - & 0.04 & - & - & - \\
\hline A. awamori & - & 0.05 & 0.03 & - & - & - & 0.08 & - \\
\hline A. oryzae & 0.27 & 0.2 & 0.14 & 0.03 & 0.19 & 0.08 & 0.15 & - \\
\hline Aspergillus sp. & 0.2 & - & - & - & 0.08 & - & - & - \\
\hline Eurotium sp. & - & 0.03 & - & - & - & - & - & - \\
\hline Penicillium glabrum & 0.32 & 0.24 & 0.30 & 0.03 & 0.46 & - & 0.27 & - \\
\hline P. purpurogenum & 1.13 & 0.57 & 0.54 & 0.54 & 1.15 & 0.73 & 0.77 & 0.54 \\
\hline P. chrysogenum & 0.14 & 0.43 & 0.32 & 0.03 & 0.08 & 0.62 & 0.04 & 0.04 \\
\hline P. funiculosum & 0.24 & - & 0.27 & 0.03 & 0.19 & 0.08 & 0.04 & - \\
\hline P. minioluteum & 0.03 & - & 0.05 & - & 0.08 & - & - & - \\
\hline P. janczewskii & 0.03 & 0.03 & - & - & - & - & - & - \\
\hline P. nalgiovense & 0.03 & - & - & - & 0.03 & - & - & - \\
\hline P. decumbens & - & 0.21 & - & - & 0.11 & - & - & - \\
\hline P. brevicompactum & - & 0.03 & - & - & - & - & - & - \\
\hline P. sacculum & 0.03 & 0.03 & 0.11 & 0.05 & - & - & - & - \\
\hline P. janthinellum & 0.20 & - & 0.05 & - & 0.08 & - & 0.08 & - \\
\hline P. herquei & - & 0.05 & - & - & - & 0.04 & - & - \\
\hline P. verruculosum & 0.24 & 0.03 & 0.11 & 0.03 & - & - & 0.12 & - \\
\hline P. pinophilum & 0.05 & 0.03 & 0.11 & 0.05 & - & - & 0.08 & - \\
\hline Penicillium sp. 1 & - & 0.03 & - & - & - & - & - & - \\
\hline Penicillium sp.2 & - & 0.22 & - & - & 0.12 & - & - & - \\
\hline Penicillium sp. 3 & 0.21 & 0.03 & - & - & - & 0.04 & - & - \\
\hline Paecilomyces marquardii & 0.03 & - & 0.03 & - & - & - & 0.04 & 0.04 \\
\hline Paecilomyces aerugineus & 0.11 & - & - & - & - & 0.08 & - & - \\
\hline Hypocrea sp.1 & - & 0.03 & - & - & - & - & - & - \\
\hline Hypocrea sp.2 & - & - & - & - & - & - & 0.04 & - \\
\hline
\end{tabular}




\section{Continued}

\begin{tabular}{|c|c|c|c|c|c|c|c|c|}
\hline Kionochaeta sp. & - & - & - & - & - & 0.03 & - & - \\
\hline Chaetomum sp. & 0.30 & - & - & - & - & 0.58 & - & - \\
\hline Trichophyton sp. & - & 0.05 & 0.03 & 0.05 & - & - & 0.04 & - \\
\hline Stachybotrys chartarum & - & 0.03 & - & - & - & - & - & - \\
\hline Microsporum sp. & 0.08 & 0.08 & - & - & - & - & 0.12 & - \\
\hline Curvularia lunata & - & 0.08 & 0.05 & - & - & - & 0.04 & - \\
\hline Fusarium oxysporum & 0.24 & 0.27 & 0.22 & 0.05 & 0.35 & 0.38 & 0.15 & 0.04 \\
\hline F. solani & 0.22 & - & - & - & - & 0.04 & - & - \\
\hline F. ciliatum & - & 0.20 & - & - & - & - & - & - \\
\hline F. culmorum & - & 0.14 & - & - & - & 0.15 & - & - \\
\hline Trichoderma koningii & 0.20 & - & 0.14 & - & - & 0.15 & - & - \\
\hline Trichoderma viride & - & 0.11 & 0.03 & - & 0.12 & - & 0.04 & - \\
\hline Trichoderma harzianum & 0.13 & 0.08 & - & - & 0.96 & 0.12 & 0.46 & 0.08 \\
\hline Talaromyces flavus & - & .20 & - & - & - & 0.08 & - & - \\
\hline Talaromyces sp. & - & 0.16 & - & - & - & - & - & - \\
\hline Cladosporium sp. & - & 0.03 & - & - & 0.08 & - & - & - \\
\hline Acremonium cellulolyticus & 0.03 & 0.03 & 0.05 & - & - & - & - & - \\
\hline Acremonium sp. & - & - & 0.03 & - & - & 0.04 & - & - \\
\hline Eupenicillium osmophilum & - & 0.08 & - & - & - & - & - & - \\
\hline Alternaria alternata & 0.57 & - & 0.03 & 0.03 & 0.04 & 0.77 & 0.12 & 0.04 \\
\hline Alternaria sp. & - & 0.03 & 0.03 & - & - & - & - & 0.04 \\
\hline Verticillium nigrescens & - & 0.11 & 0.03 & - & - & 0.04 & - & - \\
\hline Myrothecium sp. & - & 0.03 & - & - & - & - & - & - \\
\hline Nigrospora sp. & - & - & 0.03 & - & - & - & - & - \\
\hline Trichothecium sp. & - & 0.03 & 0.03 & - & - & 0.04 & - & - \\
\hline Gliocladium sp. & 0.08 & - & 0.03 & - & - & 0.04 & - & - \\
\hline Helminthosporium sp. & 0.03 & 0.03 & - & - & 0.04 & - & - & - \\
\hline
\end{tabular}

Table 3. Diversity indices of fungal communities in the two different sites.

\begin{tabular}{|c|c|c|c|c|c|c|c|c|}
\hline & \multicolumn{4}{|c|}{ Sacred forest } & \multicolumn{4}{|c|}{ Degraded land } \\
\hline & Mar-May & Jun-Aug & Sep-Nov & Dec-Feb & Mar-May & Jun-Aug & Sep-Nov & Dec-Feb \\
\hline Shannon index, $\mathrm{H}$ & 2.906 & 3.177 & 2.785 & 2.068 & 2.387 & 2.504 & 2.617 & 1.876 \\
\hline Evenness, J & 0.8545 & 0.8734 & 0.8549 & 0.7457 & 0.7969 & 0.8101 & 0.8346 & 0.7314 \\
\hline
\end{tabular}

sity, diversity, and/or activities in disturbed ecosystems $[22,23]$. Soil temperature, ambient temperature, soil moisture content and humidity were found to be positively correlated $(P<0.01, P<0.05)$ with the fungal count. Soil moisture, soil temperature, and/or substrate availability have been attributed as the most important factors that influence soil microbial growth and popula- tion density. Soil microbial diversity is generally reported to decrease with disturbance [24]. Fungi are dominant in acid soils because an acidic environment is not suitable for the existence of either bacteria or actinomycetes, resulting in the monopoly of fungi for the utilization of organic substrates [25]. Though the $\mathrm{pH}$ of forest soil was found to be lower than degraded soil, no 
correlation between $\mathrm{pH}$ and fungal population count was recorded. This result is consistent with Rousk et al. [26] who reported no correlation of fungal diversity with soil $\mathrm{pH}$.

Enzyme activities were also affected by seasons. Soil dehydrogenase, acid phosphatase and urease activity had similar seasonal patterns, with highest values in summer, lowest values in winter, and intermediate values in rainy and autumn $(P<0.05)$. These observations are in accordance with Liu et al. [24] who showed similar seasonal pattern and activity in disturbed and undisturbed soil respectively.

A higher Simpson, Shannon and evenness index in forest soil signifies higher diversity than those in the degraded soil. Fungal reports on disturbed soils have shown that the disturbance impact (especially soil degradation) might result in simplification and "trivialization" of the microfungal community, decreasing the diversity level [27]. It is known that an anthropogenic impact may mask the pristine differentiating effect of soil/lithology diversity on the structure of microfungal communities [28].

The capacity of soil to function in a productive and sustained manner is dependent on activity and high diversity of microorganisms. The vegetation of sacred grove provides a good habitat for various microbial species. The leaf litter and rhizosphere are suitable for diversity of microbial species. Whereas, barren land with rocky grassland cannot provide suitable decomposable matter for the microbial species. Thus barren land could not support sound diversity of microbial species as found in the present study. The pattern revealed in this study referred to the culturable fraction of soil fungal communities isolated by the serial dilution method. This method, in spite of certain limitations and biases such as overestimation of hardly sporulating species, loss of rare fungi, and fungi that cannot grow on culture media remains a useful approach in studying the ecology of fungal communities [29]. The culture-based technique preferably isolates microfungi from the divisions Ascomycota and Zygomycota, while basidiomycete and arbuscular mycorrhizal fungi and some ascomycetous taxons (for example, from the subdivision Pezizomycotina) are mainly missed [30]. There was considerable variation in the composition of microfungi in the two distinct soil types and culture-independent methods based on the extraction of total fungal DNA from the soil, which are intended to be employed in the nearest future, will enhance our knowledge about fungal communities in the studied soils.

\section{Acknowledgements}

Authors acknowledge the financial support received from Department of Information Technology (MC \& IT), Government of India to carry out the present study.

\section{REFERENCES}

[1] J. P. Borneman, W. Skroch, K. M. O’Sullivan, J. A. Palus, N. G. Rumjanek, J. L. Jansen, J. Nienhuis and E. W. Triplett, "Molecular Microbial Diversity of an Agricultural Soil in Wisconsin," Applied and Environmental Microbiology, Vol. 62, No. 6, 1996, pp. 1935-1943.

[2] E. Brodie, S. Edwards and N. Clipson, "Soil Fungal Community Structure in a Temperate Upland Grassland Soil," FEMS Microbiology Ecology, Vol. 45, No. 2, 2003, pp. 105-114. doi:10.1016/S0168-6496(03)00126-0

[3] M. Viaud, A. Pasquieur and Y. Brygoo, "Diversity of Soil Fungi Studied by PCR-RFLP of ITS," Mycological Research, Vol. 104, No. 9, 2000, pp. 1027-1032. doi: $10.1017 / \mathrm{S} 0953756200002835$

[4] N. S. Lord, C. W. Kaplan, P. Shank, C. L. Kitts and S. L. Elrod, "Assessment of Fungal Diversity Using Terminal Restriction Fragment (TRF) Pattern Analysis: Comparison of $18 \mathrm{~S}$ and ITS Ribosomal Regions," FEMS Microbiology Ecology, Vol. 42, No. 3, 2002, pp. 327-337. doi:10.1111/j.1574-6941.2002.tb01022.x

[5] R. D. Bardgett, C. Freeman and N. J. Ostle, "Microbial Contributions to Climate Change through Carbon Cycle Feedbacks," ISME Journal, Vol. 2, No. 8, 2008, pp. 805814. doi:10.1038/ismej.2008.58

[6] M. D. J. Lynch and R. G. Thorn, "Diversity of Basidiomycetes in Michigan Agricultural Soils," Applied Environmental Microbiology, Vol. 72, No. 11, 2006, pp. 7050-7056. doi:10.1128/AEM.00826-06

[7] R. C. Cooke and A. D. M. Rayner, "Ecology of Saprotrophic Fungi," Longman, London, 1984.

[8] J. L. Green, B. J. M. Bohannan and R. J. Whitaker, "Microbial Biogeography from Taxonomy to Traits," Science, Vol. 320, 2008, pp. 1039-1043. doi:10.1126/science. 1153475

[9] J. C. Zak, "Response of Soil Fungal Communities to Disturbance," In: G. Carroll and D. T. Wicklow, Eds., The Fungal Community: Its Organization and Role in the Ecosystem, 2nd Edition, Marcel Dekker, New York, 1992, pp. 403-425.

[10] D. L. Lodge and S. Cantrell, "Fungal Communities in Wet Tropical Forests: Variation in Time and Space," Canadian Journal of Botany, Vol. 73, No. 1, 1995, pp. 13911398. doi:10.1139/b95-402

[11] B. K. Tiwari, S. K. Barik and R. S. Tripathi, "Biodiversity Value, Status, and Strategies for Conservation of Sacred Groves of Meghalaya, India," Ecosystem Health, Vol. 4, No. 1, 1998, pp. 20-32. doi:10.1046/j.1526-0992.1998.00068.x

[12] M. B. Ellis, "More Dematiaceous Hyphomycetes," Commonwealth Mycological Institute, Kew, 1976.

[13] J. A. Von Arx, "The Genera of Fungi Sporulating in Pure Culture," Vaduz, 1978.

[14] H. L. Barnett and B. B. Hunter, "Illustrated Genera of Imperfect Fungi," 4th Edition, The American Phytopathological Society, St. Paul, 1998.

[15] M. A. Tabatabai and J. M. Bremner, "Use of p-Nitrophenyl Phosphate for Assay of Soil Phosphatase Activ- 
ity," Soil Biology and Biochemistry, Vol. 1, 1969, pp. 301-307. doi:10.1016/0038-0717(69)90012-1

[16] J. G. Casida, D. A. Klien Jr. and T. Santoro, "Soil Dehydrogenase Activity," Soil Science, Vol. 98, 1964, pp. 371376. doi:10.1097/00010694-196412000-00004

[17] J. W. McGarity and M. G. Myers, "A Survey of Urease Activity in Soils of Northern New South Wales," PIant and Soil, Vol. 27, 1967, pp. 217-238. doi:10.1007/BF01373391

[18] E. H. Simpson, "Measurement of Diversity," Nature, Vol. 163, 1949, pp. 688-690.

[19] C. E. Shannon and W. Weaver, "The Mathematical Theory of Communication," University of Illinois Press, Urbana, 1949.

[20] Q. Hammer, D. A. T. Harper and P. D. Ryan, "PAST: Paleontological Statistics Software Package for Education and Data Analysis," Palaeontologica Electronica, Vol. 4, No. 1, 2001, p. 9.

http://palaeo-electronica.org/2001_1/past/issue1_01.htm

[21] K. M. Carney and P. A. Matson, "The Influence of Plant Community Composition and Diversity on Soil Microbial Communities," Microbal Ecology, Vol. 52, 2006, pp. 226-238. doi:10.1007/s00248-006-9115-Z

[22] R. M. Atlas, A. Horowitz, M. Krichevsky and A. K. Bej, "Response of Microbial Populations to Environmental Disturbance," Microbail Ecology, Vol. 22, 1991, pp. 249256. doi:10.1007/BF02540227

[23] M. Joshi, G. S. Mer, S. P. Singh and Y. S. Rawat, " Seasonal Pattern of Total Soil Respiration in Undisturbed and Disturbed Ecosystems of Central Himalaya," Biology and Fertility of Soils, Vol. 11, 1991, pp. 267-272. doi:10.1007/BF00335846
[24] X. Liu, W. C. Lindemann, W. G. Whitford and R. L. Steiner, "Microbial Diversity and Activity of Disturbed Soil in the Northern Chihuahuan Desert," Biology and Fertility of Soils, Vol. 32, No. 3, 2000, pp. 243-249. doi: $10.1007 / \mathrm{s} 003740000242$

[25] H. Bolton Jr., J. K. Fredrikson and L. E. Elliot, "Microbiology of the Rhizosphere,” In: F. B. Metting Jr., Ed., Soil Microbial Ecology, Marcel Dekker, New York, 1993, pp. 27-63.

[26] J. Rousk, E. Baath, P. C. Brookes, C. L. Lauber, C. Lozupone, J. G. Caporaso, R. Knight and N. Fierer, "Soil Bacterial and Fungal Communities across a $\mathrm{pH}$ Gradient in an Arable Soil," ISME Journal, Vol. 4, 2010, pp. 3401352. doi: $10.1038 /$ ismej. 2010.58

[27] J. C. Zak, "Response of Soil Fungal Communities to Disturbance," In: G. Carroll and D. T. Wicklow, Eds., The Fungal Community: Its Organization and Role in the Ecosystem, 2nd Edition, Marcel Dekker, New York, 1992, pp. 403-425.

[28] O. E. Marfenina, "The Anthropogenic Ecology of Soil Fungi," Medicina Dljavseh (in Russian), Moscow, 2005.

[29] J. P. Schmit and D. J. Lodge, "Classical Methods and Modern Analysis for Studying Fungal Diversity," In: J. Dighton, J. F. White Jr. and P. Oudemans, Eds., The Fungal Community, Its Organization and Role in the Ecosystem, CRC Press, Boca Raton, 2005, pp. 193-213. doi:10.1201/9781420027891.ch10

[30] P. R. Hirsch, T. R. Mauchline and I. M. Clark, "CultureIndependent Molecular Techniques for Soil Microbial Ecology," Soil Biology and Biochemistry, Vol. 42, 2010, pp. 878-887. doi:10.1016/j.soilbio.2010.02.019 